\title{
Determination of a Minimum Detectable Activity through a Measurement of Pu Isotopes in Environmental Samples
}

\author{
M. H. Lee, E. C. Jung, and K. S. Song \\ Nuclear Chemistry Research Division, Korea Atomic Energy Research Institute, Daejeon 305-600, Korea \\ "E-mail: mhlee ákaeri.re.kr \\ Received March 2, 2008
}

\begin{abstract}
In this paper. several parameters affecting the sensitivity and determining the minimum detectable activity (MDA) for the measurement of the Pu isotopes were investigated. Among the parameters affecting the determination of the MDA values for the Pu isotopes in the environmental samples. amounts of the samples appeared to be crucial factors in decreasing the MDA values. The MDA for the Pu isotopes in the environmental samples were calculated by varying the counting time of the samples and background. The results obtained in this study can be used for an environmental radiation monitoring program regarding the level of concern for a radionuclide beyond which some action may need to be taken.
\end{abstract}

Key Words : MDA, Pu isotopes. Environnental sample

\section{Introduction}

Disintegration of a radioactivity is a random process which can be described accurately by the statistical decay law only when the number of observed events is large. for example. in a high level of radioactivity sample. However. in a very low level of radioactivity in environmental samples. the results of radioactivity measurements is likely to be misinterpreted and thus resulted inappropriate conclusions due to a random statistical fluctuation of the count rate of the background. Discussions and recommendations concerning the theory. terminology and application of detection limits have frequently appeared in literatures on radioanalytical chemistry' for more than 40 y'ears. ${ }^{1-10}$ Yet. fundamental concepts for lower limits of detection and minimum detectable activities derived statistical hypothesis testing remain unsettled and continue to be the subject of argument at many laboratories.

Detection limits for the activity concentrations of the radionuclides in radioanalytical chemistry can be defined as the smallest amount of a sample activity that will yield a netcount sufficiently large enough so as to imply its presence. This limit depends upon a critical level of activity which can be interpreted as meaning activity. The detection limits are based upon the ratio between measurements of an efficiency and background for a given instrument. The minimum detectable activity (MDA) is a level (not a limit) of activity concentration which is practically achievable by an overall measurement method. while the detection limits only provide information about the intrinsic performance of the instruments. ${ }^{11-14}$ As distinguished from the detection limits. the MDA reflects not only the instruments characteristics such as a background and efficiency. but also other factors and conditions which influence the measurements such as the amount of the samples. the chemical yield and the measuring time.

In a very low level of radioactivity in the envirommental samples. to decide whether the measured radioactivity concentration is detected from either a real radioactivity level or background. it is necessary to set up a reliable detection limit or MDA of the radionuclides. The purpose of this study was to investigate the several parameters which determine the sensitivity for the measurement of the $\mathrm{Pu}$ isotopes and to calculate the MDA values for the Pu isotopes by varying the measuring times of the background and the sample for enviroumental samples.

\section{Experimental}

Determination of the Pu isotopes in environmental samples. Before radiochemical analysis of the $\mathrm{Pu}$ isotopes. the approximate activity of the $\mathrm{Pu}$ isotopes was estimated with a low-background alpha/beta gross counting sy'stem (Oxford LB 5100). The Pu isotopes in the environmental samples were purified with an anion exchange resin and electroplated onto stainless steel platelets. ${ }^{15}$ and then. ${ }^{239.24 !} \mathrm{Pu}$ and ${ }^{38} \mathrm{Pu}$ were measured by an alpha spectrometer (Ortec. 676A). After an a-spectrometric measurement of the $\mathrm{Pu}$ isotopes on the stainless steel planchet. the $\mathrm{Pu}$ isotopes were withdrawn into an $8 \mathrm{M} \mathrm{HNO}_{3}$ solution. ${ }^{2+1} \mathrm{Pu}$ was measured ${ }^{16}$ by a liquid scintillation counter (Quantulus 1220). after removing the hindrance elements such as $\mathrm{Fe}$ and $\mathrm{Ni}$ with an exchange resin.

Calculation of the MDA for the Pu isotopes. For a $95 \%$ confidence level $(\alpha=\beta=0.05, k=1.645)$. if it is assumed that $\sigma_{\mathrm{s}} \neq \sigma_{\mathrm{s}}\left(\sigma_{\mathrm{s}} . \sigma_{\mathrm{s}}\right.$ : standard deviation of the sample and background) and $\alpha=\beta$, the MDA can be transformed into the following Eq. (1). ${ }^{14}$

$$
M D A=\frac{2.71+3.29\left(\mu_{B}\right)^{1: 2}\left(t_{S}\right)^{1:}\left(1+\frac{t_{S}}{t_{B}}\right)^{1 / 2}}{t_{S} \cdot E \cdot Y \cdot S} .
$$

where $\mu_{B}$ is the count rate of the background, $t_{S}$ and $t_{B}$ are the 
counting times of the sample and the background, $E$ is the counting efficiency, $Y$ is the chemical yield and $S$ is the amount of the sample.

In the determination of ${ }^{339,3415} \mathrm{Pu}$ and ${ }^{738} \mathrm{Pu}$ for the environmental soil samples, the values of the average chemical yield $(70 \%)$. background count rate $(0.002 \mathrm{cpm})$ and counting efficiency $(23 \%)$ for the alpha spectrometer were inserted into $\mathrm{Eq}$. (l) and the values of the MDA for ${ }^{239,2411} \mathrm{Pu}$ and ${ }^{238} \mathrm{Pu}$ were calculated. Also. after inserting the values of the average chemical yield $(70 \%)$, background count rate $(1.5 \mathrm{cpm})$ and counting efficiency $(41 \%)$ for the liquid scintillation counter into $\mathrm{Eq}$. (1). the values of the MDA for ${ }^{2+1} \mathrm{Pu}$ were calculated.

\section{Results and Discussion}

Optimum conditions for measuring $\mathrm{Pu}$ isotopes. In order to determine the $\mathrm{Pu}$ isotopes with the highest sensitivity. it is necessary to set up the optinum conditions. As shown in Figure 1, a lot of parameters are involved in determining the sensitivity of the measurement of the $\mathrm{Pu}$ isotopes. First of all. the selection of the optimum technique requires preliminary estimation of the sample activity. Approximate estimates of the $\mathrm{Pu}$ isotopes can be achieved easily using a low-background alpha/beta gross counter. before radiochenical analysis of the $\mathrm{Pu}$ isotopes.

The precision defined as the counting uncertainty in the number of counts is equal to the square root of the number of counts. ${ }^{17}$ When the number of sample counts is far greater than background counts the precision is determined by the sample counts. The precision for the counting systems is related with the counting uncertainty in the number of counts. For a large number of counts the uncertainty based on one standard can be expressed by the relative standard deviation $\left(\% \mathrm{RSD}=\sigma_{\mathrm{s}} / \mathrm{rs} \times 100, \sigma_{\mathrm{s}}\right.$ : standard deviation of sample. rs: net counting rate of sample). For the three different counting techniques the variation in precision is shown in Figure 2. Among the counting techniques. the counting system of alpha spectrometry has a lowest value of the relative standard deviation due to very low background count. The precision of counting systems such as alpha spectrometry. liquid scintillation counting and low-back-

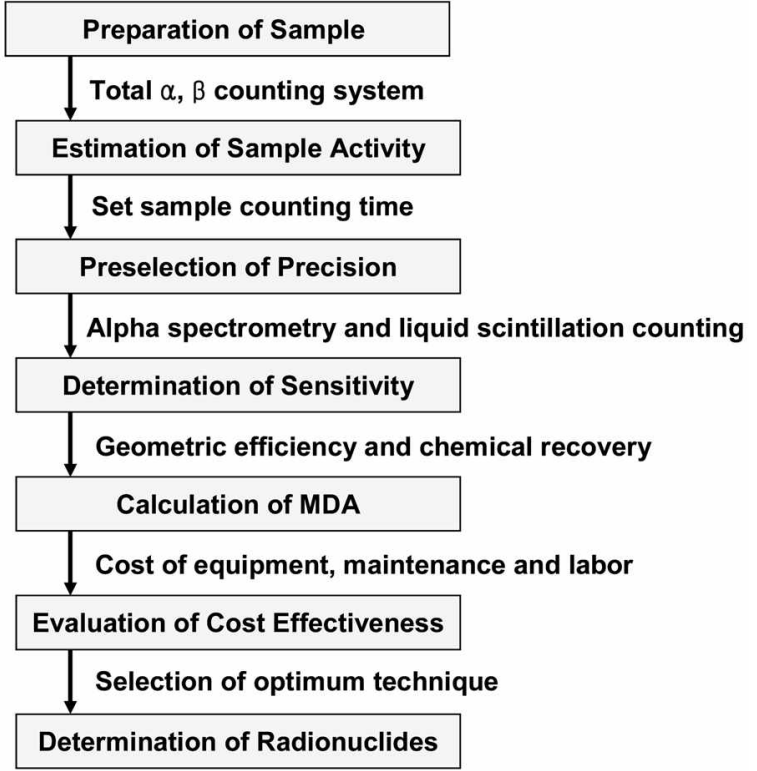

Figure 1. Parameters affecting the sensitivity of the detemination of the $\mathrm{Pu}$ isotopes.

ground alpha/beta gross counting can be improved with increasing sample activity and counting time. Therefore, when the activity decreases. for increasing the precision, the counting time has to be increased.

The figure of merit (FOM), defined as the square of the counting efficiency divided by the background in the region of interest $\left(E^{2} / \mathrm{B}\right)$. was considered to be the best indicator of determining sensitivity of the measurement of the Pu isotopes. For example, the ${ }^{241} \mathrm{Pu}$ counting channel was adjusted for the maximum value of FOM using a ${ }^{241} \mathrm{Pu}$ standard source. ${ }^{16}$ As shown in Figure 3, Left and Right channels were adjusted to 23 and 300 , respectively. in which the value of FOM was maximized.

In the measurement of the $\mathrm{Pu}$ isotopes for the environmental samples. when the number of sample counts approaches background. the detemination of the MDA is very important to decide the precision of the measurement of the $\mathrm{Pu}$ isotopes. Finally. the cost of analysis have to be considered when selecting a detemination method of the $\mathrm{Pu}$ isotopes. The analy'sis includes costs for the equipment. (a)

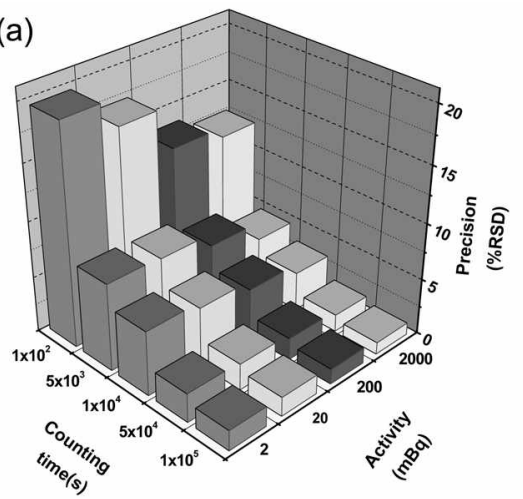

(b)

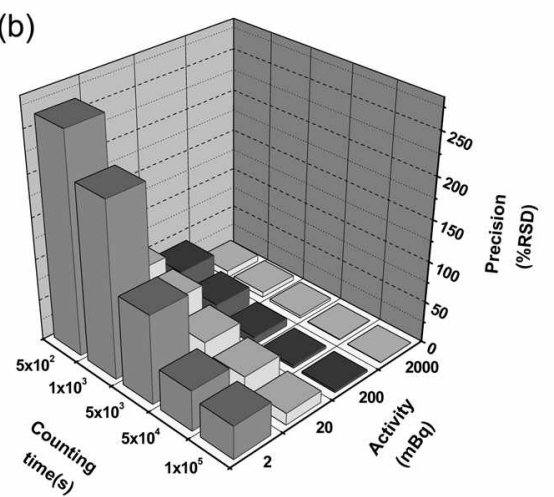

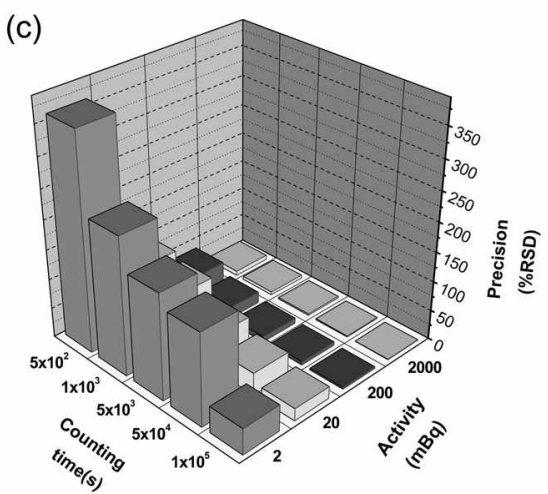

Figure 2. Variation of precision (\% RSD) observed for alpha spectrometry (a), alpha/beta gross counting (b) and liquid scintillation counting (c). 


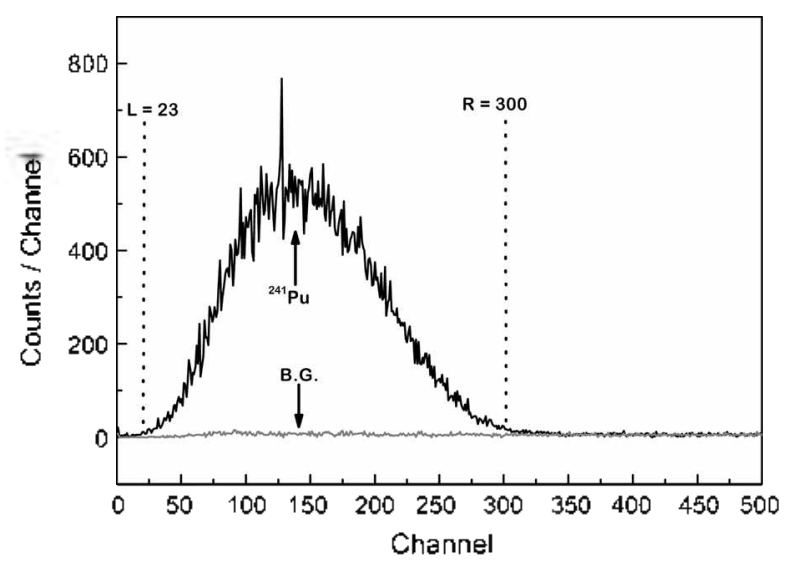

Figure 3. Left and Right channel in the beta spectrum of ${ }^{2+1} \mathrm{Pu}$ standard source [16].

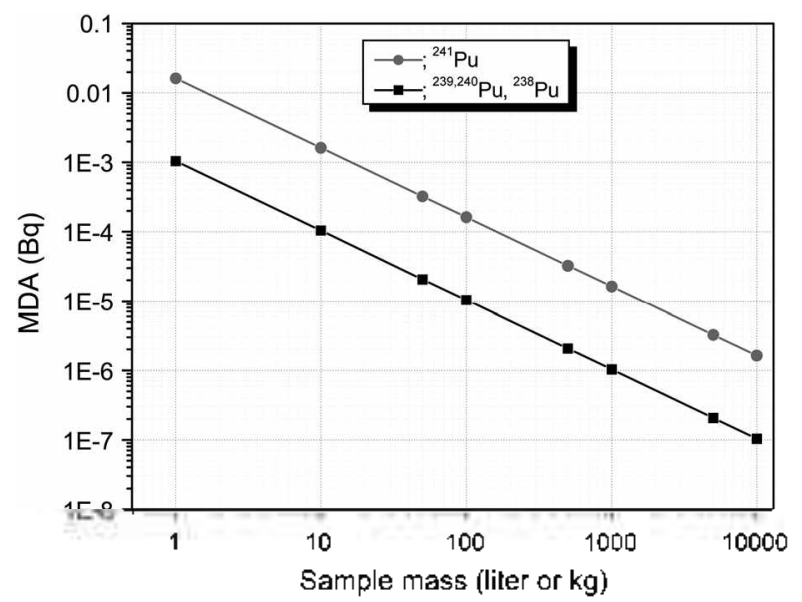

Figure 4. MDA values of ${ }^{230.240} \mathrm{Pu},{ }^{238} \mathrm{Pu}$ and ${ }^{241} \mathrm{Pu}$ plotted $v$ the sample mass.

maintenance. labor. overheads and expected demand for the service.

Parameters for the determination of the MDA value for the Pu isotopes. Among the factors that affect measurement of the $\mathrm{Pu}$ isotopes. the MDA value is very important to determine the sensitivity of the measurement of the $\mathrm{Pu}$ isotopes. A lot of variables parameters such as the counting time of the sample and the background. the count rate of the background. the detector efficiency. the chemical yield and the sample amount have an influence on the determination of the MDA. Figure 4 shows the linear relationship between the sample amount and the MDA of the $\mathrm{Pu}$ isotopes. With an increasing sample mass. the MDA was dramatically decreased. The MDA of the $\mathrm{Pu}$ isotopes was calculated from the Eq. (1). where the background counting time is equal to that of the sample. The counting time was set to be $1.000 \mathrm{~min}$ for the alpha-emitting nuclides. and $500 \mathrm{~min}$ for the beta-emitting nuclides. respectively. The MDA for ${ }^{241} \mathrm{Pu}$ was higher than that for ${ }^{239.2+15} \mathrm{Pu}$ and ${ }^{3{ }^{33 s}} \mathrm{Pu}$. since the background count rate of the liquid scintillation counter $\left(\mu_{\mathrm{B}}\right.$ $=1.5 \mathrm{cpm}$ ) was much higher than that of the alpha spectrometer $\left(\mu_{\mathrm{B}}=0.002 \mathrm{cpm}\right)$ as well as the counting time of the liquid scintillation counter $\left(t_{S}=500 \mathrm{~min}\right)$ which was shorter

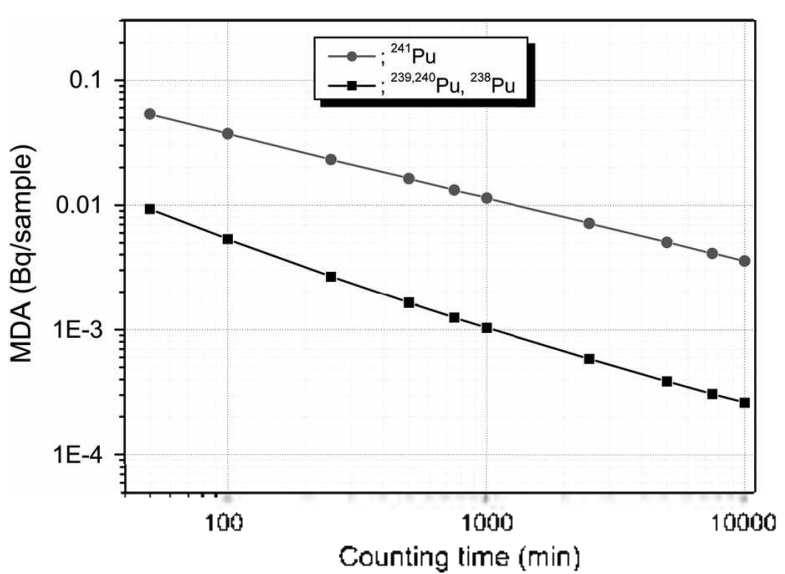

Figure 5. MDA values of ${ }^{25,92+6} \mathrm{Pu},{ }^{238} \mathrm{Pu}$ and ${ }^{2+1} \mathrm{Pu}$ plotted $w$ the counting time.

than that of the alpha spectrometer $\left(t_{\mathrm{s}}=1,000 \mathrm{~min}\right)$. although the detector efficiency of the liquid scintillation counter $(E=$ $41 \%$ ) was higher than that of the alpha spectrometer ( $E=$ $23 \%$ ).

It is interesting to compare the MDA values of the $\mathrm{Pu}$ isotopes relevant to the sample mass and those relevant to the counting time. The MDA was plotted as a function of the counting time $\left(t_{\mathrm{S}}=t_{\mathrm{B}}\right)$ in Figure 5. The MDA decreased more rapidly with the sample mass than with the counting time, compared Figure 4 with Figure 5. Thus. increasing the sample mass is more effective for reducing the MDA values than increasing the counting time in the MDA calculation, when taking into account that the background count rate may increase with the counting time.

Figures 6 and 7 show the plot of the MDA of the Pu isotopes versus the detector efficiency and the chemical yield for the $\mathrm{Pu}$ isotopes. respectively. The MDA values with the detector efficiency and the chemical yield were found to be within a narrow range. The effect of the detector efficiency and the chemical yield on the MDA values was insignificant when compared to that of the sample amount because the variations of the detector efficiency and the recovery yield were so small that they were reported as

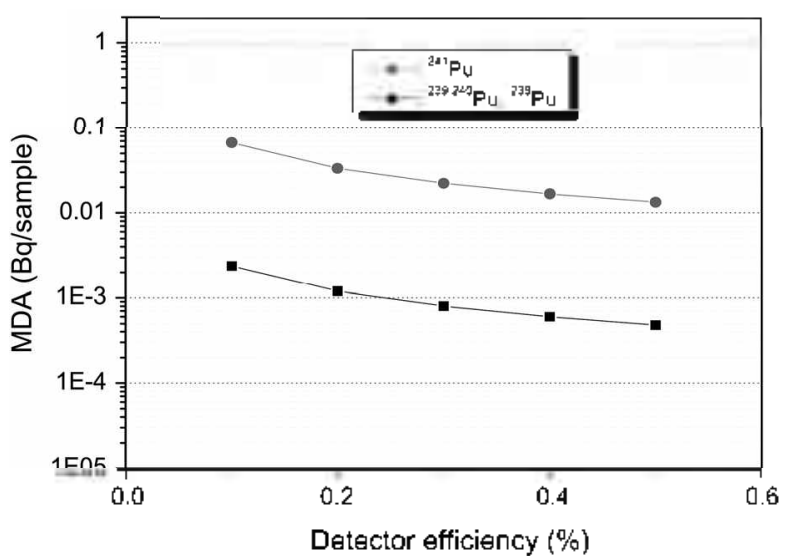

Figure 6. MDA values of ${ }^{230.210} \mathrm{Pu},{ }^{238} \mathrm{Pu}$ and ${ }^{2+1} \mathrm{Pu}$ plotted is the detector efficiency. 


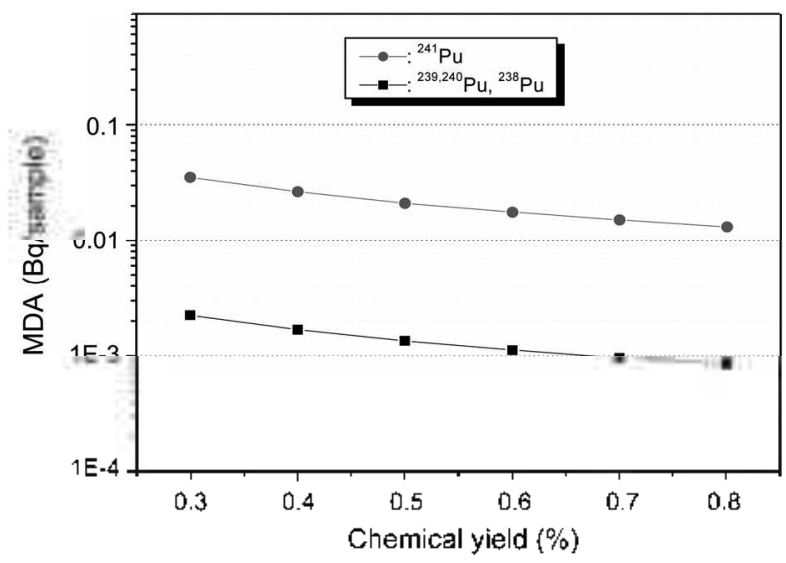

Figure 7. MDA values of ${ }^{230.240} \mathrm{Pu},{ }^{238} \mathrm{Pu}$ and ${ }^{241} \mathrm{Pu}$ plotted vs the chemical yield

reproducible for envirommental samples.

Calculation of the MDA values of the Pu isotopes by varying the counting time of the sample and background. In a Pu isotope analysis for environmental samples, it is very important that the background and sample counting times are chosen carefully. In the radioactivity analysis of the $\mathrm{Pu}$ isotopes for enviroumental samples, the background and sample counting times are set as $1.000 \mathrm{~min}$ to calculate the MDA of ${ }^{239.2+15} \mathrm{Pu}$ and ${ }^{238} \mathrm{Pu}$. But in the case of the samples containing a highly activity concentration of the Pu isotopes. it is not necessary to measure it for such a long time. In general. the allotment of background and the sample counting times is calculated by the $\mathrm{Eq}$. (2),

$$
t_{B} / t_{S}=\left(\mu_{B} / \mu_{S}\right)^{1 / z} \text {. }
$$

where $t_{s}$ and $t_{b}$ are the counting times of the sample and the background. and $\mu_{B}$ and $\mu_{B}$ are the count rate of the sample and the background.

However. in the very low background measuring system like an alpha spectrometer. the allotment of background counting time with using the Eq. (2) is calculated to be very' small value that induces a uncertainty in the measurement of the $\mathrm{Pu}$ isotopes for environmental samples. Thus. a selection of the background and the sample counting times should be optimized to obtain accurate MDA values in measuring the activity concentration of the $\mathrm{Pu}$ isotopes.

The MDA values of ${ }^{231.24(1)} \mathrm{Pu},{ }^{{ }^{23}} \mathrm{Pu}$ and ${ }^{2+1} \mathrm{Pu}$ by varying the background and sample counting times were calculated using the Eq. (1) and are shown in Figure 8 and Figure 9. respectively. The MDA values of ${ }^{23 ! !}, 241 \mathrm{Pu}$ and ${ }^{238} \mathrm{Pu}$ calculated at a fixed background counting time or sample counting time were decreased by increasing the sample or background counting time as shown in Figure 8. The MDA at a fixed $1.000 \mathrm{~min}$ of the background counting time by varying the sample counting time range from 50 to $750 \mathrm{~min}$ was higher than that at a fixed $1.000 \mathrm{~min}$ of the sample counting time by varying the background counting time in the range of 50-750 min. However. the MDA at a fixed $1.000 \mathrm{~min}$ of the background counting time by varying the sample count-

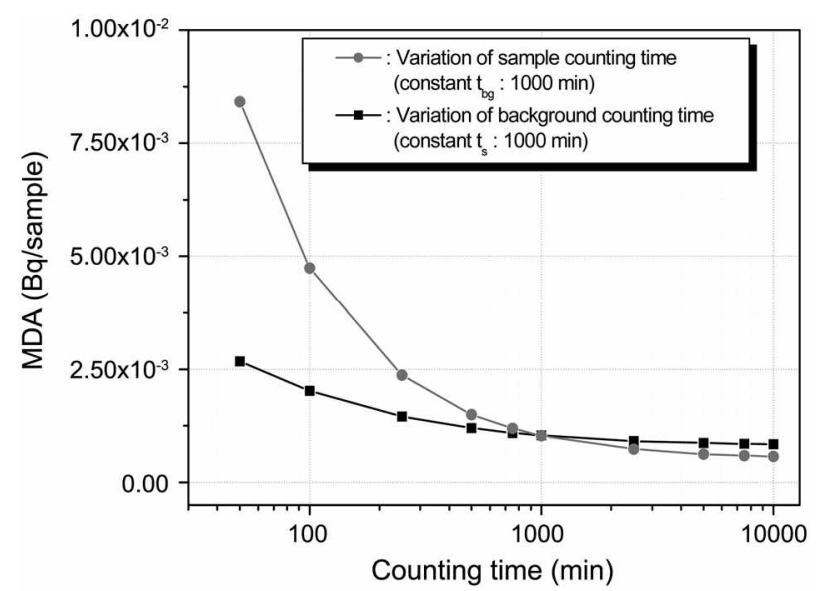

Figure 8. MDA values of ${ }^{130.240} \mathrm{Pul},{ }^{138} \mathrm{Pu}$ plotted vs variation of the sample and the background counting time.

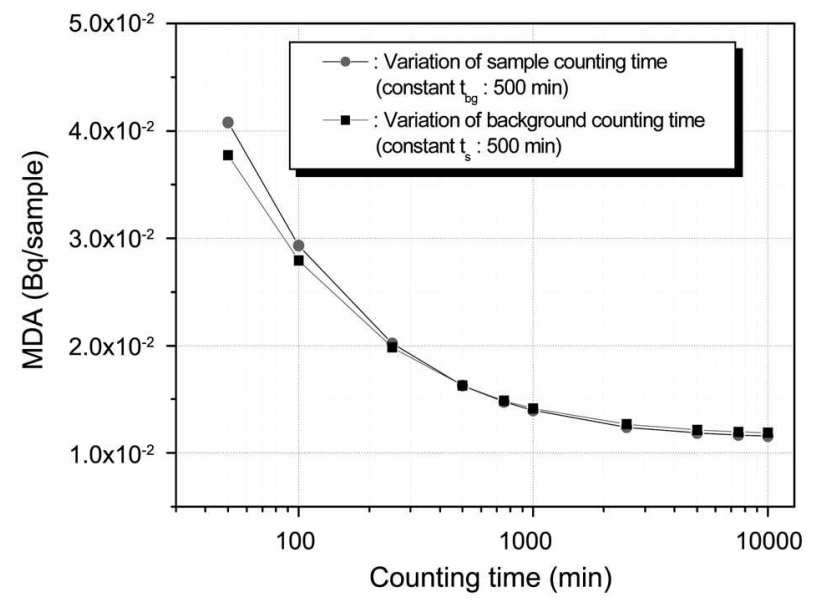

Figure 9. MDA values of ${ }^{211} \mathrm{Pu}$ plotted rs variation of the sample and the background counting time.

ing time in the range of 2.500-10.000 min was slightly lower than that at a fixed $1,000 \mathrm{~min}$ of the sample counting time by varying the background counting time in the range of 2.500 $10,000 \mathrm{~min}$. because decreasing tendency of the MDA at varying the sample counting time was larger than that at varying the background counting time.

The decreasing tendency of the MDA of ${ }^{2-41} \mathrm{Pu}$ with increasing the counting time of the sample or the background was similar to that of ${ }^{235.247} \mathrm{Pu}$ and ${ }^{238} \mathrm{Pu}$. as shown in Figure 9. Therefore, if an urgent result for the $\mathrm{Pu}$ isotopes is needed in an emergency situation or it is not necessary to measure the $\mathrm{Pu}$ isotopes for a long time due to the high activity concentration of the $\mathrm{Pu}$ isotopes in the samples. it is proper to determine the MDA at a fixed sample counting time (1.000 min) by changing the background counting time (50-750 min). Also. if the counting time requires more than 1.000 min due to a very low activity concentration of the $\mathrm{Pu}$ isotopes in a sample. to obtain a lower MDA value. the MDA should be determined at a fixed background counting time (1.000 min) by changing the sample counting time $(2.500-$ $10,000 \mathrm{~min})$ 


\section{Conclusion}

In the analysis of radioactive nuclides such as $\mathrm{Pu}$. Am. and $\mathrm{Sr}$ in a low-level environmental sample, lots of factors are involved in the sensitivity for the measurement of the $\mathrm{Pu}$ isotopes and the MDA determination. In the calculation of MDA values. sample amount was the most effective factor to reduce the MDA values. Increasing the sample amount may have economical problems and other technical problems for handling such a large anount of samples in the analytical process. In addition, if the counting time of the background and sample increases, a lower MDA is obtained. but the cost for the analysis also increases with the counting time; hence an optinization of the analytical variables for a MDA determination based on an economical point of view is needed for a low-level radioactive environumental sample.

Optimization of the counting time of the sample and background is very inportant to determine the MDA of the $\mathrm{Pu}$ isotopes. In the an emergency situation, to obtain the results of the $\mathrm{Pu}$ isotopes rapidly, it is proper to determine the MDA at a fixed sample counting time ( $1000 \mathrm{~min})$ by changing the background counting time (50-750 min). Also. in the measurement for the sample which was very low activity concentration of the $\mathrm{Pu}$ isotopes. the MDA should be deternined at a fixed background counting time (1.000 nin) by changing the sample counting time $(2,500-10.000 \mathrm{~min})$.
Acknowledgements. This study has been carried out under the Nuclear R \& D program by the Ministry of Education. Science and Technology of Korea.

\section{References}

1. Altschuler. B.: Pasternak. B. B. Health Phns 1963. 9. 293.

2. Currie. L. A Anal. Chem. 1968. 10.586.

3. Pasternack. B. S.: Harley. N. H. Nucl Inst: and Meth. 1971. 9 I. 533.

4. Head. J. H. Nucl. Inst: and Heth. 1972,98. 419.

5. Jack, J. D; Robert. L. W. Health Plhs. 1977,32. 1.

6. Show: H. F.: Toseph. L. A. Healh Phws 1977. 72.282

7. Roderick. T. A. Heath Phis 1982. 12.230.

8. Bernasconi. G.: Greates. E. D.: Sajo-Bohus. L. Nuct. Instr and 1)eth. A 1991. 307. 491 .

9. Seymour. R.: Sergent, F.: Knight. K.: Kyker. B. Radioactivity \& Radiochemisty 1992, 3, 14.

10. Friedmann. H. Health Phys 1999. 77.309.

11. Daniel. T. S.: Paul. S. S. Heath Phos 1992 63. 360.

12. Donald. A. C.: Stephanie. S. D.: Edwin. L. S. Heath Phos 1992. 63. 338 .

13. Mayer. D; Dauer. L. Healh Phys. 1993. 65.89.

14. Lee. M. H.: Cho, Y. H.: Choi. G. S.; Lee. C. W: Shin, H. S. Anal. Sci. Tech. 2001. 1H. 64

15. Lee. M. H.: Lee. C. W. Niwl Inst and Meth A $2000 .+47$. 593.

16. Lee. M. H.: Lee. C. W. Radiochim Acta 1999, 84, 177.

17. Tinker. R. A.: Smith. J. D.: Cooper, M. B. J. Radioanal. Nitcl. Chem Article 1995, 193, 329. 